\title{
Being a middle leader: exploring professional identities
}

\section{v.2}

Hugh Busher, University of Leicester, School of Education

Acc by SLAM

Approximate word length: 6300 words, ex references 


\section{Author's note}

Hugh Busher, a senior lecturer in the School of Education, University of Leicester, has research interests in leadership and organisational culture, change processes and micro-politics, teacher professional development and the creation of inclusive education.

Address for Correspondence:

Dr Hugh Busher, School of Education, University of Leicester, 21 University Road, Leicester, LE1 7RF, UK. Tel: +44 (0)116 252 3688; fax: +44 (0)116 2523653

email: hugh.busher@leicester.ac.uk 


\title{
Being a middle leader: exploring professional identities
}

\author{
Abstract \\ The pursuit of work-related self-identities are central to teachers' development of agency and \\ practice. This paper considers the work-related identities middle leaders construct - what they think \\ it means to be a middle leader - within the social and policy contexts of their secondary schools. \\ The complexity of their work becomes clear and the centrality to their work of negotiation and \\ influence - the micro-political processes of organisations - becomes stark. At the core of their \\ actions lie values that guide how they interact with colleagues, students and senior management \\ staff when trying to shape and implement departmental and school policies
}




\section{Being a middle leader: exploring professional identities}

\section{Developing professional selves in institutional contexts}

The pursuit and enactment of self-identity by people is a central aspect of their development of agency (Giddens, 1991). Greenfield (1993) perceives this process being made up of acts of individual will and practice, an existential view according to Ryan (2003). Giddens (1984) construes it as part of an interactive process in which people engage with other people to construct social systems and structures. The notion of identity derives from where and how people locate themselves within a society or a community (LaFontaine, 1985; Bourdieu, 1990), as well as from the Greek notion of persona or mask that allows people to play particular ascribe parts in a community, whether on not it is a fictional one on a stage (Hollis, 1985). So the notion of developing personhood (Aubrey et al , 2000) is complex, made up of individual and social elements and, in the contexts of institutionalised work, of elements that are related to a person' work-related life and elements that are not. The latter are often not visible to work-based colleagues.

People develop their work-related (professional) self-identities through their interactions with other people in a variety of milieu through time. These identities are grounded in people's individual histories, personalities and work-related experiences (Nias, 1999; Goodson, 1992; Thomas, 1995a), including, for staff in schools, their experiences as students in various institutions (e.g. Gersten, 1995). Students and staff use these dialogic and reflective ways to develop core educational and social values to guide their actions consciously and unconsciously. (Hodgkinson, 1991; Begley, 1999). In doing this, as Smyth et al (2000) point out, teachers (and they could have included students and support staff, too) 'have to contend with the power relationships that operate in schools and educational systems' (p.149), as well as with contextual factors of race, gender, creed and socio-economic status (SES) (Smyth et al, 2000).

To people workers, such as teachers and leaders at any level in schools, understanding people's actions in terms of how they are constructing their self identities in particular contexts is essential to being able to work with them successfully. However this is not a value-free process. The bully and the autocrat as well as the marketing manager and the diplomat, to be successful in their practices, have to have sound understandings of other people. Some use this to exert power over people, to coerce them (Etzioni, 1961), others use it to manipulate or manage them. Blase and Anderson (1995) suggest leaders in schools use power in a variety of ways to shape the work of colleagues and students. The sources of power on which people can draw are multifaceted and only partially related to the authority that is associated with the formal posts they hold (French and Raven, 1968; Busher, 2001). One of these is knowledge about persons. The choices that individual leaders make about how to use their knowledge of students' and colleagues' developing work-related selves involve value-laden or moral decisions about how to act to create more or less harm and in whose interests. Teachers are sharply aware of this when working with students. Middle leaders, too, on some of whom this paper focuses, also have to be conscious of this when working with teachers and other staff as well as with students. Middle leaders encompass a wide range of people in schools such as subject leaders, heads of department, pastoral leaders (e.g. heads of year), SENCOs (Bennett. et al, 2003). Busher and Saran (1995) stretched the list to include some members of the support staff, such as site supervisors, too. 
In the view developed here, persons, not systems, are perceived as the centres of knowing and the constructors of meaning (Harrison, 1994:177) in and of institutions. So schools as communities are constructed through dialogical processes between individuals and between individuals and collectivities, such as departments or groups of students or external stakeholders. The outcomes from these evolving discussions are shaped more by the differential access to power which participants can gain to assert their preferred definitions of situations than by the coherence of an argument or the rationality of a suggested approach to resolving problems that may be put forward by participants in the dialogue. Outcomes also depend on policy imperatives imported into schools from the macro socio-political contexts outside them. It leads Ribbins (1999) to argue that all decision-making in schools involves political acts that encompass value-laden choices between different possible actions. For example, allocating resources to some people and projects rather than to others, since only some can be afforded, involves moral as well as financial and personnel judgements about which people should receive and who should be deprived.

Schools in this paper are construed as sites of policy processes (Grace, 1995; Bowe and Ball, 1992) that are sustained by asymmetrical and negotiable relationships of power between school members. In these institutions organisational structures are no more, though no less, than the historical outcomes of negotiative processes, the reflections of past and present hierarchical relationships within the school that are sustained and eroded by changing socio-political contexts. The external contexts relevant to a study in England, UK, include central and local government policies as well as shifts in public attitudes and the socio-economic status of members of the communities which each school serves (Riley et al. 2000; Busher and Barker, 2003). At national government level are to be found policies such as the National Curriculum, OFSTED inspections, Key Stage Three strategies and the introduction of performance management into schools, as well as curriculum frameworks policed by public examination boards on behalf of central government. At local or regional government level are policies defining from which communities a schools' students come, what levels of support particular students might receive, and how schools can most successfully improve the quality of learning and teaching. The internal policy contexts are constructed and projected by a school's senior management team (Grace, 1995). Like leaders at all levels in a school middle leaders mediate the values and demands from these contexts to their colleagues, students and their students' parents and carers, as well as taking account of their colleagues', students' and students' parents' values and beliefs.

The construction of school policies, teaching and learning practices, and school cultures and subcultures, is a moral and a political activity involving the managing, monitoring and resolving of value conflicts, where values are defined as concepts of the desirable (Hodgkinson, 1999:7). Although this work is carried out by all participants in a school some, especially formally designated leaders at all levels, have more access to power to influence the shaping of these processes. Construction involves leaders confronting moral dilemmas about the distribution of people, resources and power. Resolving these ethically and transparently in keeping with previously established social and moral norms of the school community seems to be central to successful leadership in English schools. MacBeath and MacDonald (2000) suggest that decision-making based on the use of moral authority grounded in shared professional and social values is most likely to promote the social cohesion and collegiality that can lead to improved practice.

Such approaches to decision making are more likely to be sustained by the values embedded in distributed leadership (Gronn, 2000; Woods et al, 2003) than by leadership styles that are more autocratic or corporate in focus. Distributed leadership embodies particular approaches to working with and using power with other people (Blase and Anderson, 1995). This includes fostering positive interpersonal relationships based on shared values between people to construct a sense of 
community (Sergiovanni, 2001), and allowing leadership for particular aspects of joint activity to be shared amongst members of the group or community (Gronn, 2002). This cannot, however, overlook the force of personality which some people project whatever their formal post in an institution, and has led Allix (2000) to question the extent to which transformational leadership in the hands of such a person may be as coercive as other non-consultative approaches to leadership. In communities where there is trust between members Smyth et al, (2000) argue that participants are likely to sustain a critical dialogue between themselves, whatever position they hold, about the practices of teaching and learning and the development of those to better meet the needs of all student. Hopkins (2001) perceive trust as crucial to creating cultures in schools and departments that can facilitate the implementation of organisational change and the improvement of teaching and learning practices. Gunter et al (2001) translate this into teachers' practices in the classroom, discussing how teachers as leaders of learning in the classroom - meaning any site where formal learning is intended to take place - work successfully with students to construct learning processes that are meaningful and relevant to all of them.

The same approaches to leadership that are likely to improve the quality of teaching and learning are likely to foster staff professional development, leading to the emergence of what have been called professional learning communities (Senge, 1990; Bottery, 2003). Empowering other people creatively to develop themselves and their performance of practice requires leaders to foster particular organisational cultures that have been described as collegial (Hargreaves, 1994) and that incorporate collaborative styles of working (MacGregor, 2000). Murphy (1992) suggests that leaders who veer towards being creative and empowering might be 'servant leaders' or educative leaders (Duignan and McPherson, 1992) who try to promote the interdependence and professional development of colleagues (Ribbins, 1992) within the constraints of the internal organisational and extra-organisational policies and structures that currently exist. However, given that some people in school have greater access to power and authority than others, it is doubtful to what extent genuine collegiality or democracy can be achieved in hierarchical organisations such as schools

\section{Research design and methods}

This study focuses on the work of six middle leaders (three men and three women) in departments in four secondary schools in the Midlands of England, UK, in 2001/02, following the work of Measor and Sikes (1992). Siskin (1994) points out that subject areas are critical sites for developing teachers' practices. As the study included subject and pastoral leaders, the term middle leader is preferred except where indicating a person's particular status. The study used an interpretative approach to explore how people constructed and construed meanings in their social situations, following Ribbins (1997) view that is only by listening to people's voices that one really finds out what it is like to be and to work in an institution like a school. This study merely sets out to record and analyse what appeared to be happening in the departments in the schools in this study, not to predict or propose what practices and enacted values might lead to particular outcomes.

Participants were selected opportunistically from among schools and departments that regularly have PGCE students on placement with them. They came from a variety of different sized departments, following the views of Busher and Harris (1999), and included two pastoral departments (Sixth Forms); a history department; a humanities faculty (including history, geography and RE departments); and an English department. I interviewed them on one occasion and then work-shadowed them for one day mid-week, observing them teach and work with their departmental colleagues and with students in lessons, interviewing them again at the end of the day. I also interviewed some of their departmental colleagues (10 in all: four men and six women) and 
one member of senior staff each (four men and one woman) about their work, finding these participants by using snowball sampling. Most of these collateral interviews took place during the days I was in school visiting the middle leaders. Although the snowball sampling minimised ethical problems of talking with people about others without permission, and was an expeditious means of finding such participants, it left the middle leaders with power to shape the view I might have of them through their selection / non-selection of participants. The triangulation of middle leaders' views of their work with that of staff colleagues was intended to strengthen the authenticity of the study by addressing doubts about the trustworthiness of single authored texts (Thomas, 1995b). It allowed me to check their espoused theories of practice against their enacted theories (Schon, 1987). All the interviews were semi-structured, as were the observations. The interviews were taperecorded and transcribed. The observations were recorded by hand in real time. In addition relevant documents about each school and department were collected. In this paper mainly middle leaders' voices are heard although observation of teachers and students' interactions with the middle leaders underpin the discussion and cast interesting lights on the leaders' proclaimed values and views on teaching and learning.

\section{Exploring the identities that middle leaders construct}

\section{Biographies and values}

Middle leaders biographies made a deep impact on their professional identities (Busher, 2002). Many made reference to their childhood and how this had affected their views and values on teaching, learning and leading. One referred to her father's love of knowledge and the location of the family home. The latter encouraged in her interest in outdoor activities. Another, female subject leader, commented how her parents were always interested in how well she was doing at school, amongst other things checking what homework was set and whether or not she had done it.

The values that the middle leaders carried with them into teaching, were derived from a variety of sources. Some came from their family backgrounds. Others came from teachers with whom they had worked as students when at school themselves or in higher education and from teachers with whom they had worked early in their careers. The values to which they laid claim covered a range of aspects of their work: working with students; the importance of their subject area; teaching; working cultures in their subject area; and the allocation of resources to students (Busher, 2003).

In particular, their reflections on their experiences at school and university had shaped their views of successful teaching. Several of them chose to develop their own practice for teaching and managing out of the creative and caring examples modelled by their teachers who had mediated the educational contexts they had experienced during their struggles as students.

\section{Why they chose to become a middle leaders}

Several participants identified skills they possessed that they thought suited them for leadership, including those of being effective organisers outside the classroom. Others celebrated the creativity of being a middle leader

making up schemes [of work] ... Having the chance to have a budget, plan it, implement it and see it actually happening in front of your eyes [male subject leader] 
Others commented on the broader perspectives on education holding a middle leader post gave them, or had given them, as well as the opportunities it offered to understand their work in wider policy contexts and to interact more with those contexts.

Some of them perceived promotion to middle leadership as an opportunity to assert their voice and their ideas more strongly within their school. Some claimed this had not been apparent to them in their first years of teaching, but other, usually more experienced teacher had helped them to realise the possibilities. Promotion shaped their sense of their work-related identity, their views of themselves being bound up with the formal positions they held in the school hierarchy.

\section{Being a middle leader}

The middle leaders in this study thought there were six key functional aspects to their work - see Table One - and held remarkably homogeneous views on their preferred departmental cultures. This surprising homogeneity in a study that was sited in well-scattered schools within a region may be due to the way in which the middle leaders were sampled. These views were largely supported by the other teachers and senior staff in the study and by observations of the middle leaders working with students and colleagues.

\section{Table One Key functional aspects of middle leaders' work (about here)}

\section{1) Developing and projecting a vision}

Middle leaders considered it important to have a clear vision, encapsulating certain educational and social values, for the development of their departments, and to project this to their colleagues. They thought they should have a view of how their department was going to improve the curriculum, although they then tried to work with colleagues to achieve this.

In subject departments the values were related to the subject area and to its diverse pedagogic practices. For example, one middle leaders wanted to

make my subject accessible to all students [using] a variety of teaching styles that apply to different learners. Some get a real kick out of writing reams ... [some] are more into hands on learning, like games ... discussion work, card activities ... Yet ... they are still learning about the past ... still developing key historical skills [female subject leader]

In pastoral departments the vision focused on values concerned with student personal growth and development based on a watchful trustfulness by teachers of students' efforts to learn.

Other values middle leaders wanted to project related to 'professional' practice by colleagues. One expected his colleagues

to treat the RE lessons with vigour and seriousness ... to be professional and as efficient as possible, within limits of time ... I expect them to follow the schemes of work, which has not always happened, and I expect them to do the assessments. I expect them to file the resources! [male subject leader] 
These values were linked to social ones about how colleagues should interact with each other. This middle leader thought that good interpersonal relationships between staff made it easier for them to work as a departmental team.

To create and implement policy successfully in their departments, middle leaders claimed that they had to have the energy to want to do so - a notion of will power. They wanted to implement their own vision of a successful department. This they thought could be most successfully achieved by working with and through colleagues to ensure that policies were successfully carried out. In one faculty subject leaders met weekly formally but also held a lot of informal conversations to clarify:

our priorities for the department. Then we will feed that down to the department [staff] to ... take on board their ideas ... we may have to listen to the department and [change the] way we will do it ... it could be about workload, which is a real issue ... The bottom line is I am the head of faculty and this is how we are going to do it, like it or not [female subject leader]

The emphasis here seems to have been on tough but open consultation with colleagues about decisions. In other cases it was having the energy to persuade colleagues to uphold previously agreed departmental practices such as putting resources away in designated locations or completing student assessments on time. Yet others perceived this projection of power as taking the form of creating a strategic framework for action by departmental colleagues and then checking up that targets had been met, as well as providing support to colleagues to help them meet these.

The asymmetrical power relationships in departments were most visible when middle leaders were co-ordinating and monitoring the progress of work. Through monitoring student performance, middle leaders were able to exercise surveillance of staff performance, as middle leaders and staff acknowledged:

Making sure that everybody has ... information on the computer. Reports sorted out. People have done what they should be doing, like assessments at the right time; books marked; meeting requirements for teaching [female subject leader]

However teachers in the departments seemed to accept this surveillance as a legitimate part of the middle leaders' work in its current socio-political contexts so it did not appear to threaten the collaborative cultures of the departments. This acceptance seems to have been facilitated by the consultative manner in which these processes were constructed and implemented by middle leaders.

3) Working with staff - the core of middle leadership

Negotiating and interacting with colleagues lay at the core of middle leaders' work with staff. Some perceived it as quite challenging. According to one female subject leader the hardest part of her job was to persuade her colleagues to follow the same policy and practice, particularly as the department was made up of 'quite diverse people', and impossible to get them all moving at the same speed towards agreed educational goals. Middle leaders countered this tendency to dispersion of practice by colleagues by using their access to various sources of power. This was most visible when they acted as agents for a school's senior staff to ensure teachers in their departments were 
producing ... everything connected with their subject ... in the classroom, and the paperwork, and what the [school] hierarchy needs, and what the LEA or government requires [male subject leader]

This structuring of practice and performance included planning curriculum targets in keeping with public examination bodies and the National curriculum at the appropriate Key Stage for the students, and monitoring progress on meeting these targets to ensure that teachers and students did not become the focus of criticism by the school's senior management. Middle leaders' colleagues welcomed the planning of work for the department to create targets for the students and staff as it gave them an administrative framework within which they could focus on working with their students.

If control and constraint was one element to middle leaders practice, support and facilitation of the work of colleagues and students was another equally important one. They supported staff in various ways, including setting work for supply teachers and disciplining students who disturbed other teachers' lessons:

because I am the [teachers'] line manager ... and knowing staff as I do, I know which kids I need to sort out [female subject leader]

Observations indicated that middle leaders spent a considerable amount of their non-contact time dealing with students who flouted school rules and contacting and relating to parents because of this.

To help colleagues meet curriculum targets middle leaders tried to manage their departments effectively - as is discussed below -, acted as advocates for their colleagues' views to the senior management team, and worked with colleagues to resolve problems that threatened the achievement of the targets, as their colleagues acknowledged.

These instrumental activities were supported by the middle leaders' interpersonal relationships with their colleague teachers and support staff. The values they expressed through these helped to construct collaborative departmental cultures, which the middle leaders and their colleagues said they preferred. Both commented how people in their departments liked working together and sharing some social time together, in some cases out of school hours.

\section{4) Co-ordinating departments effectively}

To carry forward the enterprise of improving teaching and learning for all students, middle leaders thought they had to manage their departments effectively. To do this they carried out a considerable range of administrative tasks:

filing and buying the books. ... the exam entries, the mocks [exams] ... I have created a shelf of specialist RE books for people taking religious assemblies ... I find myself flying the flag for RE [male subject leader]

and created centralised management systems: 
central resources and common schemes of work, common assessment, common [student] records that we put on to Excel that can be monitored to see how different classes are doing and that staff are meeting deadlines [female subject leader]

Although this restricted the autonomy of teachers, many accepted it as a necessary and normal part of working in a school department and some welcomed the clear administrative framework as a support to shape their decision-making.

I have got a folder of all the assessments at the front and the scheme of work and all the various work sheets for different abilities [of students] ... [Subject leader] also looks for textbooks. All the textbooks are in a box ... and on the wall there is a sheet where we can book the textbooks out [female teacher]

The centralised management systems were intended to ensure appropriate resources were allocated equitably. As well as physical resources middle leaders provided intellectual resources including specialist knowledge on the subject and its pedagogy, as several teachers acknowledged, by

trying to share ideas, mainly through schemes of work, putting teaching methods down, for example [female subject leader]

The allocation of resources was a value-laden process, not just a technical one, as several middle leaders acknowledged:

Value for money ... I would hope in every school, that we ... spend the money fairly and equally across all the pupils [male subject leader]

However such communitarian values were in conflict with the market-oriented policies of central government

5) Mediating contexts: engaging in arenas

Middle leaders in this study engaged in an endless round of negotiation with people in various arenas. These ranged from classroom arenas (any site where formal learning was intended to take place), usually with students; to departmental arenas, usually with teacher colleagues, which has already been discussed; to school organisation policy arenas that involved a wide range of staff such as support staff, other middle leaders, senior staff and school governors; to local or civic social and policy arenas; and to national policy arenas, often concerning syllabus changes and the entry of students to examinations.

In the school organisation policy arena middle leaders had multi-faceted and ambiguous relationships with senior management. At times they acted as agents for the senior staff:

who feeds to the department the aims of the school, where the school is going, and how we can bring those aims down through into the department and in to a classroom level [female subject leader]

In part this was because they were dependent on senior staff for the successful implementation of preferred departmental policies 
for instance, we are able to bid for money through a capital bid and I have always been very well supported by SMT in the budget [female subject leader]

and for developing a strategic vision and plan for their departments. One middle leader had difficulty

organising mock exams for RE, which is only a GCSE short course, for one year, but it is compulsory for all students ... and they [Senior staff] would not timetable them at the same time as the other mocks but expected them to be done in lesson time [male subject leader]

However they also acted as advocates for their colleagues with senior staff, representing their views on school policy and defending them against senior management prejudices and policies.

Middle leaders negotiated with colleagues in other departments, formally through school middle leaders meetings, when trying to implement departmental policy such as the undertaking of fieldwork with a group of students.

From the civic and national arenas middle leaders mediated the impact of different policies on their and their colleagues' work with students, for example, by modifying aspects of the curriculum to reflect local sensibilities and perspectives. However several said that the flood of new government initiatives during the 1990s had taxed their resourcefulness

the amazing amount of new initiatives ... The amount of paper work, the amount of admin. involved ... has changed beyond all recognition. ... we [now] have less time to spend with pupils, and more of our time is being spent on what we would call bureaucracy [male subject leader]

Apart from the National Curriculum middle leaders referred to government literacy, numeracy and Key Stage Three strategies, the impact of OFSTED inspections, and the impact which performance management was having on their relationships with colleagues.

And after the last OFSTED I am going to have to monitor their marking and observe, which should be an interesting challenge [female subject leader]

In some cases OFSTED inspections had enhanced the influence of middle leaders in the school because inspectors' reports had praised the work of their departments.

\section{6) Being a teacher}

Several middle leaders considered that being a good teacher was essential for being respected and regarded as effective by his or her colleagues.

Not the most innovative but the most effective. If you can show that to colleagues through the response of the students that you teach [male subject leader]

Observational data showed that middle leaders used a variety of teaching strategies to encourage students to engage with learning through differentiating the curriculum to suit their particular learning needs. Students appeared to spend most of their time on task in well-organised lessons that 
had clearly defined objectives, sometimes put on a board at the start of a lesson, and suitable resources for the intended variety of activities.

Middle leaders debated the impact of holding office on the quality of their teaching. Some thought it improved their work because they were more aware of the broader educational and social contexts. Others thought that it made them less effective teachers for those students who needed more detailed preparation of their work. They no longer had time available for this, spending their creative energy on managing their departments. Observed middle leaders were frequently late for their lessons as a result of trying to meet other teachers' needs although this did not appear to affect their control of their classes. They often had to undertake administrative tasks during lessons, when pupils were getting on with their own work, in order to meet deadlines imposed by senior staff or outside sources. They spent a lot of their non-contact time visiting colleagues, senior colleagues and administrative offices, and pursuing troublesome students on their own or colleagues' behalf sometimes to arrange detentions or contact parents.

\section{Reflections}

What emerges from this small scale study of middle leaders in some secondary schools is the importance to their professional identities of the educational and social values they developed through their historical biographies and their professional experiences. In doing this they located themselves in their educational communities and donned the mantles of their respective ascribe roles to play their part in the theatre of school politics. Not surprisingly, then, the subject leaders emphasised the importance of their subject to the centrality of their work and those of their colleagues, while the pastoral leaders emphasised the importance of students' social and personal development. All the middle leaders felt obliged to act as advocates for their departmental colleagues and policies to the senior management team in their schools while also acting as agents for senior management in representing school policies to their departmental colleagues. This janusfaced performance by middle leaders has been noted elsewhere by Gunter (2001).

Central to middle leaders' professional identities was continuing to be experienced and effective classroom practitioners who could give advice and guidance to their colleagues and to students on this basis. Some of the younger subject leaders were criticised by a few of their older colleagues for lacking this experience, even when their colleagues acknowledged they were successful teachers. Middle leaders did not locate themselves as part of the management echelon of the school, identifying themselves instead with the teachers. This identification emerged most clearly in the language they did not use. They did not refer to themselves as managers. Indeed when they and their departmental colleagues talked about managers they referred almost exclusively to 'senior managers', meaning vice principals and principals in their schools. Middle leaders located themselves and their work as part of that carried out by the professional workers or cadres of the school - and their colleagues in their departments seemed willing to support this view. They perceived middle leaders as one of themselves, not part of the management hierarchy, although middle leaders visibly occupied promoted posts, in some cases of some seniority in their schools. This construction of professional identity raises some interesting questions about the extent to which middle leaders can or should be considered teacher leaders, as is discussed below.

In this context it is not surprising that middle leaders preferred to facilitate collaborative cultures within their departments (MacGregor, 2000). The cultures could not really be described as collegial since the asymmetrical power relationships in the departments were clearly visible and often acknowledged, even in small matters such as who chaired meetings. None the less the cultures 
seemed to have shared norms and values that were student centred, promoted equitable support to students, focused on improving the quality of teaching and learning to meet inclusively the needs of students, and fostered staff development. These cultures showed social cohesion amongst staff not only in their professional work but also, to some extent, in their social contacts outside work, indicating the development of a sense of professional community in these departments certainly amongst some of their members.

Part of the development of that shared culture seemed to be the emergence of distributed leadership (Gronn, 2002), with various teachers in each department taking responsibility for different aspects of the department's operations as well as engaging in discussions about departmental policy through formal and informal consultations. None the less the distribution of leadership remained influenced by the asymmetrical power relationships that existed in the departments, and was openly acknowledge, that invested formally designated middle leaders with access to a wider range of sources of power than many of their colleagues. Middle leaders and their colleagues perceived their style of leadership as one that was consultative and transformational, promoting the core values discussed earlier. In part this was enacted by trying to help colleagues to enhance their capacities as members of the department through attending courses and in part by sharing in the leadership of the department. Middle leaders perceived themselves as 'primus inter pares', although none of them used that term, a form of leadership that Gronn (2002) identifies as indicative of the institutionalised practices of distributed leadership.

Yet the departments were not cosy clubs but arenas of policy-making and negotiation which purposefully focused on implementing certain educational and social values to enhance the quality of teaching and learning for all students, a characteristic of learning communities noted by Bottery (2003). Further there were potent and accepted inequalities of power between middle leaders and their colleagues. These emerged most clearly when the former exercised managership' (Gronn, 2003) to create an organisational framework for the effective running of their departments against which they monitored its performance and the performance of their colleagues. This was the enactment of middle leaders' passions to create effective departments that reflected their values and their positive and negative experiences of departments and teachers earlier in their careers and when students themselves. This tends to substantiates Greenfield's (1993) existential notion of leaders having to have the will to power if they are to be successful, but it does place limits on the extent to which the leadership of these departments can be considered distributed and the extent to which their cultures can be considered genuinely collegial (Hargreaves, 1994), although they certainly were collaborative and at least professionally cohesive.

That such naked use of power over people (Blase and Anderson, 1995) did not appear to wreck the collaborative cultures that operated in the departments may have been due to the legitimacy that teacher colleagues accorded the middle leaders' actions. There was a form of consent to their actions that was frequently renewed through middle leaders' formal and informal interactions with their colleagues in the specific policy contexts of the school. This consent was based on several strands, firstly on that of consultation itself. Secondly it acknowledged that such actions fitted with current socio-political and educational policies in the macro-sphere: middle leaders and teachers were demonstrably keenly aware of these. Thirdly it accepted the sense of moral mission that middle leaders claimed to improve the quality of teaching and learning for all students and to create effective departments.

The location of middle leaders in the internal policy processes of schools is important for an effective organisational analysis of schools. So it is important, finally, to consider whether they can or should be considered teacher leaders. Muijs and Harris (2003) think that teacher leaders can 
include middle leaders so long as those middle leaders continue to have a major part of their work based in the classroom and seek to work collectively with their teacher colleagues. In this study all the middle leaders spent at least two thirds of their time teaching. Several, indeed complained that they did not have sufficient time to carry out the supervisory work with colleagues that they needed to. On the other hand, Katzenmeyer and Moller (2001), admittedly writing in an American context where middle leaders are often no longer classroom practitioners, thought middle leaders could not be considered teacher leaders, although they conceded that where middle leaders did spend a substantial mount of their time in the classroom they might be described as teacher leaders. Only Frost and Durant (2003) firmly confine the notion of teacher leadership to people holding nonpromoted posts in schools but who take a lead in decision-making in a school beyond the doors of their classrooms. They argue this is presenting an alternative understanding to hierarchically based conceptions of leadership, disregarding the impossibility of having institutions without asymmetrical power relationships, and therefore hierarchies. On balance then it might be reasonable to consider the middle leaders in this study as teacher leaders.

However, a different question is whether it is useful to consider middle leaders as teacher leaders when analysing the dynamics of educational organisations. To do so obscures the important differences there might be between leadership offered by post holders individually, with their access to various sources of power including those that arise through the offices they hold (Busher, 2001); leadership offered conjointly by formally designated leaders with their colleagues (Gronn, 2002; Woods et al, 2003); and those people in non-promoted posts, be they teachers, support staff or students, who offer leadership in a variety of ways to the whole school or to a department of it. From this perspective of analytical clarity it is probably more satisfactory not to refer to middle leaders as teacher leaders. None the less the centrality to their professional identities of being classroom teachers and not managers has to be acknowledge if scholars are to better understand the dynamics of school decision-making and the implementation of policies for the improvement of teaching and learning for all. 


\section{References}

Aubrey, C. David, T. Godfrey, R and Thompson, L. (2000) Early childhood educational research: Issues in methodology and ethics (London, RoutledgeFalmer)

Begley, P. T. (1999) Introduction in P. T. Begley and P. E. Leonard (eds) (1999) The Values of Educational Administration London: Falmer Press

Bennett, N. Wise, C. Woods, P.A. and Newton, W. (2003) Leading from the middle: A review and analysis of the evidence Paper presented at the British Educational Research Association Annual Conference, Edinburgh, September 2003

Bowe, R. and Ball. S with Gold, A. (1992) Reforming education and changing schools: Case studies in policy sociology London: Routledge

Blase, J. and Anderson, G. L (1995), The micro-politics of educational leadership: From control to empowerment (London: Cassell)

Bottery, M. (2003) The leadership of learning communities in a culture of unhappiness Paper given to the ESRC Seminar Series Challenging the orthodoxy of school leadership: Towards a new theoretical perspective, National College for School Leadership, UK, June 2003

Bourdieu, P (1990) The logic of practice, tr. Richard Nice Cambridge: Polity Press

Busher, H (2001) The micro-politics of change, improvement and effectiveness in schools, in Bennett, $\mathrm{N}$ and Harris, A (eds) School effectiveness and school improvement: searching for the elusive partnership (London: Continuum)

Busher, H (2002) Being and becoming a subject leader: histories and ethnographies paper given at the British Educational Research Association (BERA) Annual Conference, Exeter, 2002

Busher, H (2003) Value driven leadership, in M. Brundrett, M. Leask and I. Terrell (eds) (2003)

Learning to lead in the secondary school London: Routledge Falmer

Busher, H and Barker, B (2003) The crux of leadership: Shaping school culture by contesting the policy contexts and practices of teaching and learning Educational Management and Administration 31 (1) pp.51-65

Busher, H and Harris, A (1999) Leadership of School Subject Areas: tensions and dimensions of managing in the middle School Leadership and Management 19 (3) 305-317.

Busher, H and Saran, R (1995) Managing with support staff in H. Busher, and R. Saran, (eds)

Managing teachers as professionals in schools London: Kogan Page

Duignan, P and Macpherson, R (1992) Educative leadership: Practical theory for new administrators and managers London: Falmer Press

Etzioni, A. (1961) A comparative analysis of complex organisations, New York: Free Press

French, J and Raven, B (1968) The bases of social power in Cartwright, D and Zander, A (eds)

Group dynamics, research and theory (London: Tavistock press)

Frost, D and Durrant, J (2003) Teacher leadership: Rationale, strategy and impact School

Leadership and Management, 23 (2) 173-186

Gersten, F (1995) The pupil experience: A view from both sides in D. Thomas (ed) (1995)

Teachers' stories Buckingham, Open University Press

Giddens, A. (1984) Constitution of society: Outline of the theory of structuration Cambridge: Polity

Press

Giddens, A. (1991) Modernity and self-identity: Self and society in the late modern age Cambridge:

Polity Press

Goodson, I. (ed)(1992) Studying teachers' lives London: Routledge

Grace, G. (1995) School leadership: Beyond educational management: An essay in policy scholarship, London: Falmer Press.

Greenfield, T. in Greenfield, T. and Ribbins, P. (eds.) (1993) Greenfield on Educational

Administration London: Routledge 
Gronn, P (2000) Distributed properties: A new architecture for leadership Educational Management and Administration 28 (3) 317-338

Gronn, P (2002) Distributed leadership as a unit of analysis The Leadership Quarterly 13 423-451 Gronn, P (2003) Leadership: Who needs it? Paper given to the ESRC Seminar Series Challenging the orthodoxy of school leadership: Towards a new theoretical perspective, University of Birmingham, UK, February 2003

Gunter, H., McGregor, D. and Gunter, B. (2001) 'Teachers as leaders: A case study', Management in Education, 15 (1) 26-28.

Hargreaves, A. (1994) Changing teachers, changing times: Teachers' work and culture in the postmodern age, London: Cassell.

Harrison, B.T. (1994) Applying critical ethics to educational management Educational Management and Administration 22 (3) 175-183

Hodgkinson, C (1991) Educational leadership: the moral art. Albany: State University of New York Press

Hodgkinson, C (1999) The triumph of the will: An exploration of certain fundamental problematics in administrative philosophy in P. T. Begley and P. E. Leonard (eds) (1999) The Values of Educational Administration London: Falmer Press

Hollis, M (1985) Of masks and men in M. Carrithers, S. Collins, and S. Lukes, (eds) (1985 The category of the person: Anthropology, philosophy history Cambridge: Cambridge University Press Hopkins, D (2001) Improving the Quality of Education for All (London, David Fulton)

Katzenmeyer, M and Moller, G (2001) Awakening the sleeping giant: Helping teachers develop a leaders $2^{\text {nd }}$ Edn. Thousand Oaks, Ca: Corwin Press

LaFontaine, J.S. (1985) Person and individual; Some anthropological reflections in M. Carrithers, S. Collins, and S. Lukes, (eds) (1985 The category of the person: Anthropology, philosophy history Cambridge: Cambridge University Press

MacBeath, J and MacDonald, A (2000) Four dilemmas, three heresies and a matrix, in K.A. Riley and K.S. Louis (eds)(2000) Leadership for change and school reform London: Routledge Falmer MacGregor, J (2000) The challenge of collaboration: What encourages joint work between teachers? Paper presented at the BEMAS Research Conference, 2000, Robinson College, Cambridge, UK

Measor, L. and Sikes, P. (1992) Visiting lives: Ethics and methodology in life history in I. Goodson (ed)(1992) Studying teachers' lives London: Routledge

*Murphy, J (1992) serv ant leadership

Muijs, D and Harris, A (2003) Teacher leadership - improvement through empowerment? An overview of the literature Educational Management and Administration 31 (4) 437- 448

Nias, J (1999) Becoming a Primary school teacher, in J. Prosser (ed.) School culture London: Paul Chapman

Ribbins, P (1992) What professionalism means to teachers. Paper given at the British Educational Management and Administration Society (BEMAS) Fourth Research Conference, University of Nottingham, 1992

Ribbins, P (1997) Introduction in P. Ribbins (ed) Leaders and leadership in the school, college and university London: Cassell

Ribbins, P (1999) Foreword, in P. T. Begley and P. E. Leonard (eds) (1999) The Values of Educational Administration London: Falmer Press

Riley, K.A., Docking, J, and Rowles, D (2000) Caught between local education authorities: Making a difference through their leadership, in K.A. Riley and K.S. Louis (eds)(2000) Leadership for change and school reform London: Routledge Falmer

Ryan, J (2003) Greenfield and the Post-modern: Order, anarchy and inquiry in educational administration, In R. Macmillan (ed) (2003) Questioning Leadership: The Greenfield legacy London, Ontario: University of Western Ontario, the Althouse Press 
Schon, D (1987) Educating the Reflective Practitioner: Towards a new design for teaching and learning in the professions (San Francisco Ca, Jossey Bass)

Senge, P (1990) The fifth discipline (New York: Doubleday)

Sergiovanni, T (2001) Leadership, what's in it for schools? London: Routledge /Falmer

Siskin, L. (1994) Realms of knowledge: Academic departments in secondary schools, London:

Falmer Press

Smyth, J. Dow, A. Hattam, R. Reid, A. and Shacklock, G. (2000) Teachers' work in a globalising economy London: Falmer Press

Thomas, D. (1995a) Teachers' stories studies in D. Thomas (ed) (1995) Teachers'stories

Buckingham, Open University Press

Thomas, D. (1995b) Treasonable or trustworthy text: Reflections on teacher narrative studies in D.

Thomas (ed) (1995) Teachers' stories Buckingham, Open University Press

Woods, P. A, Bennett, N. Harvey, J.A. Wise, C. (2003) Understanding distributed leadership Paper presented at the British Educational Association Annual conference, Edinburgh September 2003 
Table One Key functional aspects of middle leaders' work

1. Having a vision for their department;

2. Having the will to use power: Managership

3. Working with staff to implement action;

4. Co-ordinating and implementing action effectively;

5. Mediating contexts: engaging in arenas;

6. Being a teacher - a successful model for colleagues 